\title{
High Resolution Computed Tomography (HRCT) Evaluation of Suspected Interstitial Lung Disease Cases.
}

\author{
Sunil $\mathbf{M}^{1}$, Mishal Mohammed ${ }^{2}$, Y Thiruvarul $\left.\right|^{3}$ \\ ${ }^{1}$ Associate Professor, Department of Radiodiagnosis, Al Azhar Medical College and Superspeciality hospital, Thodupuzha, ${ }^{2}$ Associate Professor, Department of \\ Radiodiagnosis, Karuna Medical College, Vilayodi, Chittoor, Palakkad, Kerala, ${ }^{3}$ Professor, Department of Radiodiagnosis, Rajah Muthiah Medical College, \\ Chidambaram.
}

\section{Abstract}

Background: Interstitial lung disease (ILD) refers to a large group of diseases that causes scarring of lung tissue. Diagnosis of exact etiology of ILD is usually by clinico-radiologic-pathologic correlation. HRCT of Lung plays a crucial role in diagnosis of etiology of ILD \& determining prognosis. Objective: To describe the HRCT findings in clinically suspected cases of ILD and to compare the role of HRCT with Chest X ray in diagnosis of ILD. Subjects and Methods: A descriptive study was conducted among 50 consecutive, consenting patients with clinical suspicion of interstitial lung disease. History and clinical details of all study participants were noted and first examined with chest radiography and then exposed to HRCT. The data thus collected was properly coded and entered in Microsoft Excel and analysis was done using the software SPSS version 16.0. Results: Mean age of the study population was 48.84 years (SD=14.46).60\% of the study participants were males. Specific diagnoses could be made in $25.7 \%$ of abnormal case with radiograph and clinical correlation and in $57 \%$ with HRCT and clinical correlation. Most common pattern identified was reticular (60\%) and most common anatomical area of involvement identified was lower lobe (54.28\%). Most common etiology among the cases was idiopathic pulmonary fibrosis (20\%) followed by sarcoidosis (11.4\%). Conclusion: Idiopathic pulmonary fibrosis, sarcoidosis and Hypersensitivity pneumonitis along with non specific type were the most frequent types of ILD identified in the study. The current study demonstrates a better diagnostic efficacy for HRCT when compared to chest $\mathrm{X}$ ray in the evaluation of interstitial lung disease.

Keywords: High resolution computed tomography, interstitial lung disease, Idiopathic pulmonary fibrosis, Reticular pattern.

Corresponding Author: Dr. Mishal Mohammed, Associate Professor, Department of Radiodiagnosis, Karuna Medical College, Vilayodi, Chittoor, Palakkad, Kerala.

Received: January 2019

Accepted: February 2019

\section{Introduction}

Interstitial lung disease remains a major challenge to radiologists, clinicians and pathologists, with several hundred conditions causing diffuse lung disease, hence requiring extensive investigations, including combination of laboratory tests, physiologic studies, radiographic examinations, and invasive procedures, including fiber optic bronchoscopy with trans bronchial biopsy(TBB), bronchoalveolar lavage (BAL), or both, or open-lung biopsy, for the accurate diagnosis. ${ }^{[1]}$ It is well-documented that chest radiographs are limited in both their sensitivity and specificity in patients who have diffuse lung disease and it may be normal during the early course of the disease. Even when detected in Chest X ray, it's often unable to identify the specific etiology. ${ }^{[2]}$ It has also been shown that $10-20 \%$ of patients who have diffuse lung disease suspected on chest radiographs subsequently prove to have normal lung biopsies. ${ }^{[3,4]}$ High resolution computed tomography (HRCT), on the other hand, is now widely recognized as more sensitive and specific than Chest $\mathrm{X}$ ray for the assessment of such patient. ${ }^{[5,6]}$ Hence this study was conducted to describe the findings of HRCT in clinically suspected diffuse lung disease cases and to compare the role of HRCT with Chest X ray in diagnosis of ILD.

\section{Subjects and Methods}

After getting approval from the Institutional ethical committee, a descriptive study was conducted in the Department of Radiodiagnosis, RMMCH, Chidambaram, among 50 patients who were clinically suspected to be having interstitial lung disease, during the period March 2011 to August 2012.

\section{Sample Size:}

In a study conducted by Patil et al assessing HRCT findings in patients with clinical suspicion of interstitial lung disease, $74 \%$ showed reticular opacity. ${ }^{[7]}$ Using this data minimum sample required for the current study was calculated using the formula $\mathrm{n}=\frac{\mathrm{Z} \alpha^{2} \mathrm{PQ}}{\mathrm{d}^{2}}$

taking ' $d$ ' as $13 \%$ which is less than $20 \%$ of $\mathrm{P}, \mathrm{n}=44$.

Hence this study was conducted among 50 patients with clinical suspicion of interstitial lung disease. 
Sunil et al; Itigh Resclution Camputed Tamagraphy Evaluation of Suspected Interstitial Lung Disease

\section{Sampling Technique:}

50 consecutive, consenting patients with clinical suspicion of interstitial lung disease sent from the General Medicine department, RMMCH, Chidambaram were recruited into the study.

\section{Study Procedure:}

After getting approval from the Institutional ethical committee and Head of the department- Radiodiagnosis, RMMCH, Chidambaram, a descriptive study was conducted among 50 patients who were sent for taking HRCT Chest, from General Medicine department, with clinically suspicion of interstitial lung disease. Informed consent was taken from all the study participant after excluding those with cardiac/renal failure and malignant diseases. Case records of the patients were obtained and all relevant clinical information were noted. All study participants were first examined with chest radiography and then exposed to HRCT. HRCT was performed with patients in supine position and breath-holding at full inspiration using PHILIPS dual slice CT scanner. The parameters used were: $1.5 \mathrm{~mm}$ collimation, $10 \mathrm{~mm}$ interspace, high spatial frequency reconstruction and window settings at $-700 / 1000$, $-600 / 1500 \& 50 / 350 . H . U$. Suspicious cases with dependent density were subjected to prone scan. Pattern of parenchymal involvement and anatomic distribution was noted. Final diagnosis was made by clinico-radiologic correlation.

\section{Statistical Analysis:}

The data was properly coded and entered in Microsoft Excel. Further analysis was done using the software SPSS version 16.0. Qualitative variables were expressed as percentages and quantitative as mean with standard deviation.

\section{Results}

The study sample consisted of 50 patients with clinical suspicion of interstitial lung disease. Mean age of the study population was 48.84 years $(\mathrm{SD}=14.46$ years) and majority (34\%) belonged to 41-50 years age group. Study population consisted of 30 males (60\%) and 20 females (40\%). Only $10 \%(n=5)$ of the study population were involved in the occupation hazardous to lung. Among the study subjects $50 \%$ presented with both exertional dyspnea and nonproductive cough.

Chest $X$ ray was abnormal in 21 cases $(42 \%)$, equivocal in $14(28 \%)$ cases and normal in 15 cases $(30 \%)$. Definite diagnosis of ILD could be reached only in 9 cases $(25.7 \%)$ with chest $\mathrm{X}$ ray alone.

On the other hand HRCT showed abnormalities suggestive of ILD in 35 cases $(70 \%)$ and was normal in remaining 15 cases $(30 \%)$. Among the cases with abnormalities, specific etiology of ILD could be made out in 20 cases (57\%). The mean age of the cases in whom HRCT abnormality was identified was 50.4 years ( $\mathrm{SD}=13.8$ years). Male: Female ratio among the cases with abnormality was $1.7: 1$.
Table 1: Distribution of abnormal cases according to the pattern identified in HRCT chest.

\begin{tabular}{|c|c|}
\hline Pattern & No of cases (\%) \\
\hline Rcticular & $18(51.4 \%)$ \\
\hline Nodular & $21(60.0 \%)$ \\
\hline Ground glass & $12(34.3 \%)$ \\
\hline Consolidation & $8(22.9 \%)$ \\
\hline Mosaic pattern & $2(5.7 \%)$ \\
\hline
\end{tabular}

Table 2: Distribution of abnormal cases according to the anatomical area involvement as identified in HRCT chest

\begin{tabular}{|c|c|}
\hline Distribution & No of cases (\%) \\
\hline Upper & $7(20 \%)$ \\
\hline Lower & $19(54.3 \%)$ \\
\hline Central & $6(17.14 \%)$ \\
\hline Peripheral & $9(25.7 \%)$ \\
\hline Diffuse & $6(17.14 \%)$ \\
\hline
\end{tabular}

Table 3: Distribution of abnormal cases according to the specific diagnosis made by HRCT chest.

\begin{tabular}{|c|c|}
\hline Disease & No of cases (\%) \\
\hline IPF & $7(20 \%)$ \\
\hline Sarcoidosis & $4(11.4 \%)$ \\
\hline Hypersensitivity pneumonitis & $3(8.6 \%)$ \\
\hline Alveolar proteinosis & $2(5.7 \%)$ \\
\hline Silicosis & $2(5.7 \%)$ \\
\hline Connective tissue disorder & $2(5.7 \%)$ \\
\hline Equivocal & $15(43 \%)$ \\
\hline
\end{tabular}

\section{Figures - Representative cases}

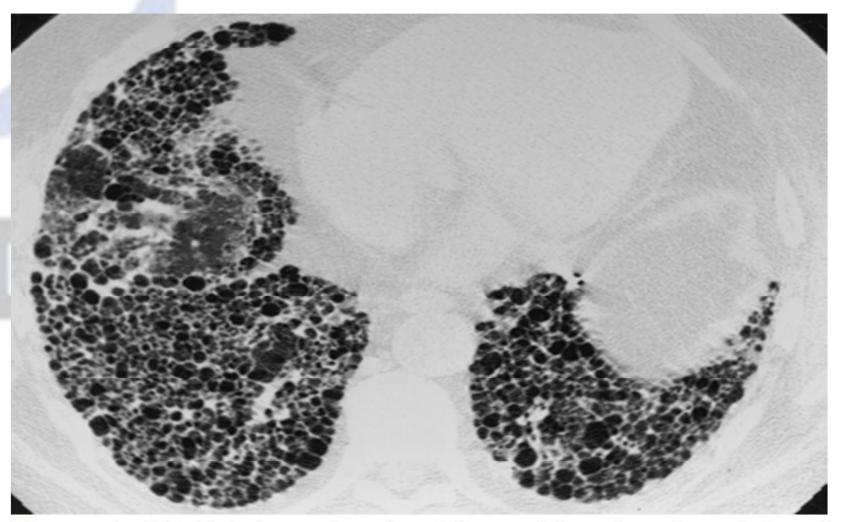

Figure 1: HRCT chest showing bilateral basal and peripheral honeycombing along with traction bronchiectasis Findings are in favour of idiopathic pulmonary fibrosis.

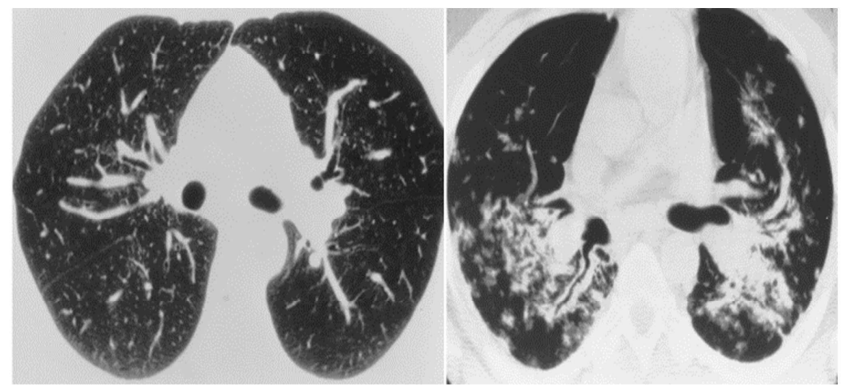

Figure 2: HRCT chest showing miliary nodules and conglomerate masses in the upper and central region predominantly along central bronchovascular bundles. Few subpleural nodules and bilateral mediastinal lymphadenopathy also seen. Findings are in favour of sarcoidosis. 
Among those with abnormal HRCT chest, the most common pattern identified was reticular $(60 \%)$ followed by nodular pattern $(51.42 \%)$ [Table 1] Among those with reticular pattern $55.5 \%$ were coarse, $33.3 \%$ nodular and $11.1 \%$ were smooth. On the other hand, among those with nodular pattern $47.6 \%$ were perilymphatic, $38.09 \%$ were centrilobular and $14.2 \%$ were random. The most common anatomical area of involvement identified was lower lobe $(54.3 \%)$ followed by peripheral area $(25.71 \%)$ and upper lobe $(20 \%)$ [Table 2]

Among the 20 cases, in which definite etiology could be made out by HRCT, most common etiology were idiopathic pulmonary fibrosis (20\%), Sarcoidosis (11.4\%) and hypersensitivity pneumonitis (8.6\%) 「Table 37 .

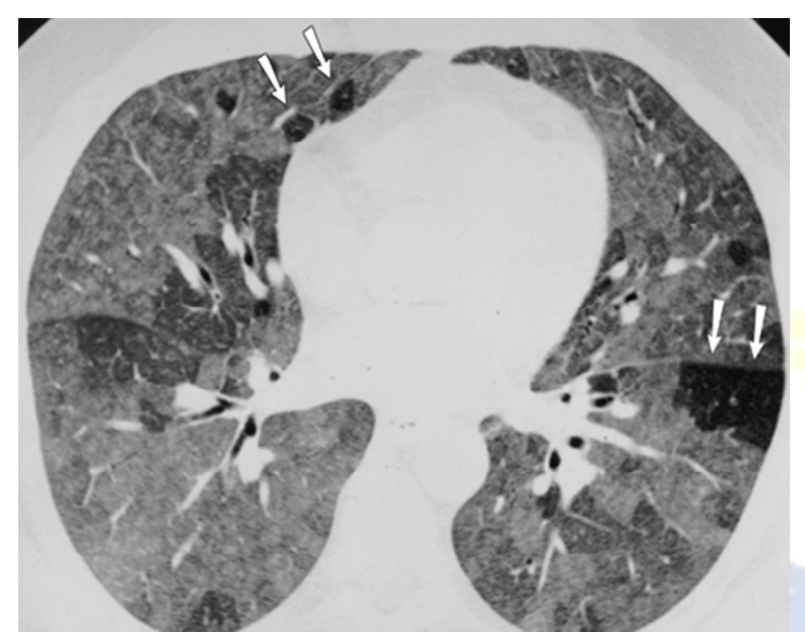

Figure 3: HRCT chest showing diffuse centrilobular nodules with ground glass opacity and mosaic perfusion in the lower zones. Findings are in favour of hypersensitivity pneumonitis.

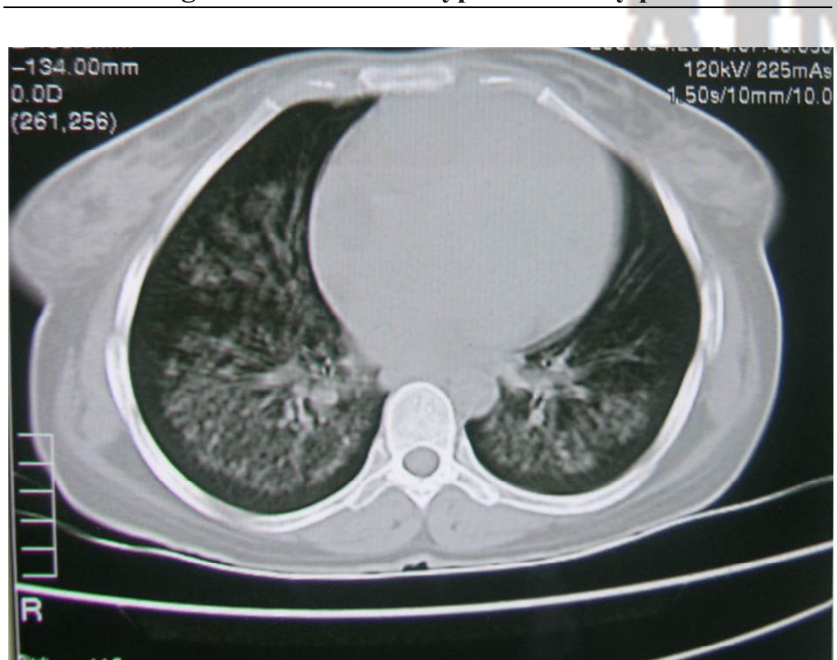

Figure 4: HRCT chest showing patchy and geographic areas of ground glass opacity with interlobular septal thickening within the areas of ground glass opacity. Distribution was more of central in nature. Findings are in favour of alveolar proteinosis.

\section{Discussion}

This study was conducted in 50 patients with a mean age of
48.84 years ( $\mathrm{SD}=14.46$ years), in whom there was clinical suspicion of ILD. Similar age of presentation was noted by Thomeer $\mathrm{M}$ et al, who reported the average age of presentation to be 52 years. ${ }^{[8]}$

Slight male predisposition noted among the cases was in line with studies conducted by Roelandt $\mathrm{M}$ et al, Coultas $\mathrm{DB}$ et al as well as Thomeer $\mathrm{M}$ et al. ${ }^{[8-10]}$

In chest radiograph examination, a high percentage of patients $(28 \%)$ were reported as equivocal. HRCT picked up lesions in all these cases but most of them were grouped under non-specific category, who definitely need biopsy to get a definitive diagnosis. On the other hand HRCT showed abnormalities suggestive of ILD in 35 cases (70\%).

Nine cases of specific diagnoses were made with radiograph and clinical correlation, whereas 20 were made with HRCT, which corresponds to $25.7 \%$ and $57 \%$ respectively. This shows the better diagnostic efficacy of HRCT which correlates with the study done by Mathieson et al. ${ }^{[1]}$

In the diagnosed cases, 7 had IPF (20\%), 4 sarcoidosis (11.4\%), 3 Hypersensitivity pneumonitis (8.6\%), 2 each of alveolar proteinosis, silicosis, CTD (5.7\% each) and 15 equivocal (43\%).Distribution of various etiology correlates well with the study by Coultas et al. ${ }^{[10]}$

HRCT contributes to the differential diagnosis of diffuse lung disease on the basis of the recognition of the main pattern, associated findings and distribution of the lesions. Four main categories of features may be described at CT: reticular pattern, nodular patterns, increased lung attenuation and decreased lung attenuation. ${ }^{[12-15]}$ Out of 35 abnormal cases on HRCT most of them showed a reticular and nodular (60\%and $51.2 \%$ respectively) patterns. This can be explained by the higher proportion of IPF and sarcoidosis identified in the study.

Nine cases of reticular pattern showed coarse reticular sub type mainly due to large numbers of IPF cases and 20 cases showed perilymphatic and centrilobular sub pattern of nodules (Sarcoidosis, silicosis and non specific conditions). Nineteen patients showed lower zone anatomic distribution while 9 showed peripheral distribution, which is due to the majority in fibrotic conditions and hypersensitivity pneumonitis. $100 \%$ of patients with IPF showed lower and peripheral predominance. This correlates with the study done by Nishimura et al. ${ }^{[16]}$ Seven patients showed upper lobe predominance due to sarcoidosis and silicosis.

\section{Conclusion}

In the current study, involving 50 clinically suspected cases of interstitial lung disease, abnormality was detected by HRCT in 35 cases, with specific diagnosis in $57 \%$ of cases. On the other hand specific diagnosis could be reached in only $25.7 \%$ of abnormal cases by chest radiography. The most common pattern identified was reticular (60\%) and most common anatomical area of involvement identified was lower lobe (54.28\%). Most common etiology among the cases was idiopathic pulmonary fibrosis $(20 \%)$ followed by sarcoidosis $(11.4 \%)$. 
Sunil et al; Ftigh Resalution Camputed Tamagrayphy Evaluation of Suspected Interstitial Lung Disease

Histopathological correlation was not done in the current study, which could have reduced the number of nonspecific cases.

\section{Acknowledgments:}

The authors acknowledge the support received from the staff - Department of Radiodiagnosis, RMMCH, Chidambaram in the completion of the study. The hospitable nature and cooperation of the study participants are also acknowledged at this moment.

\section{References}

1. Ryu JH, Danicls CE, Hartman TE, Yi ES. Diagnosis of interstitial lung diseases. Mayo Clin Proc. 2007 Aug;82(8):976-86.

2. Raniga S, Sharma P, Kaur G, Arora A, Khalasi Y, Vohra P V. "Interstitial Lung disease (Ild) in Rheumatoid arthritis (Ra)"- a study of thirty cases. Indian J Radiol Imaging. 2006;16(4):835-9.

3. Epler GR, McLoud TC, Gaensler EA, Mikus JP, Carrington CB. Normal chest roentgenograms in chronic diffuse infiltrative lung disease. N Engl J Med. 1978 Apr 27:298(17):934-9.

4. Edward A et al. Open Biopsv for Chronic Diffuse IAtrativ; Lung Disease: Clinical, Roentgenographic, and Physiological Cowelations in 502 Patients. Ann Thorac Surg Available from: https://www.annalsthoracicsurgery.org/article/S0003-4975(10)61291$\mathrm{X} / \mathrm{pdf}$

5. King TE. Clinical Advances in the Diagnosis and Therapy of the Interstitial Lung Diseases. Am J Respir Crit Care Med. 2005 Aug 1;172(3):268-79.

6. Bhat IM, Bhat JA, Shamshad M, Malik AA, Mir S. Role of IIighresolution Computed Tomography Chest in Interstitial Lung

Diseases. Int J Sci C Study [Internet]. [cited 2019 Jan 14];4(2). sn.com/uploads/2/0/1/5/20153321/ijss_may_oa04.pdf

7. Pankaj Badarkhe-Patil, Dayanand Kawade,. HRCT Assessment of Interstitial Lung Diseases. Int J Contemp Med Res. 2016 Aug;3(8):2426-30

8. Thomeer M, Demedts M, Vandeurzen K, VRGT Working Group on Interstitial Lung Diseases. Registration of interstitial lung diseases by 20 centres of respiratory medicine in Flanders. Acta Clin Belg. 2001 Jun;56(3): 163-72.

9. Roelandt M, Demedts M, Callebaut W, Coolen D, Slabbynck H, Bockaert J, et al. Epidemiology of interstitial lung disease (ILD) in flanders: registration by pneumologists in 1992-1994. Working group on ILD, VRGT. Vereniging voor Respiratoire Gezondheidszorg en Tuberculosebestrijding. Acta Clin Belg. 1995;50(5):260-8.

10. Coultas DB, Zumwalt RE, Black WC, Sobonya RE. The epidemiology of interstitial lung diseases. Am J Respir Crit Care Med. 1994 Oct;150(4):967-72.

11. Mathieson JR, Mayo JR, Staples CA, Müller NL. Chronic diffuse infiltrative lung disease: comparison of diagnostic accuracy of CT and chest radiography. Radiology. 1989 Apr;171(1):111-6.

12. Webb WR, Muller NL, Naidich DP. High-resolution CT of the lung. Philadelphia: Lippincott Williams and Wilkins; 2001

13. Stern EJ, Swenson SJ, Collin J, Franquet T, Kazerooni E, McGuinness G. High-resolution CT of the chest: comprehensive atlas, 2nd ed. Baltimore: LWW, 2001

14. Mayo JR. Webb WR, Gould R, et al. High-resolution CTof the lungs: an optimal approach. Radiology 1987; 163:507-10.

15. Webb WR, Stein MG. Finkbeiner WE, et al. Normal and diseased isolated lungs: high- resolution CT. Ra־diology 1988; 166:81-7.

16. Nishimura $\mathrm{K}$, Kitaichi M, Izumi T, Nagai S, Kanaoka M, Itoh H. Usual interstitial pneumonia: histologic correlation with highresolution CT. Radiology. 1992 Feb;182(2):337-42.

Copyright: (C) the author(s), publisher. Asian Journal of Medical Radiological Research is an Official Publication of "Society for Health Care \& Research Development". It is an open-access article distributed under the terms of the Creative Commons Attribution Non-Commercial License, which permits unrestricted non-commercial use, distribution, and reproduction in any medium, provided the original work is properly cited.

How to cite this article: Sunil M, Mohammed M, Thiruvarul Y. High Resolution Computed Tomography (HRCT) Evaluation of Suspected Interstitial Lung Disease Cases. Asian J. Med. Radiol. Res. 2019;7(1):01-04.

DOI: dx.doi.org/10.21276/ajmrr.2019.7.1.1

Source of Support: Nil, Conflict of Interest: None declared 